\title{
Visual Literacy and Virtual Rephotography
}

\author{
Gary McLeod \\ University of Tsukuba, Japan
}

\begin{abstract}
Rephotography is a varied set of practices that begin with taking one or more pictures of the same subject. Valued for generating conversations in-situ about a place over time, recent large-scale migration to online learning draws attention to rephotography's virtual modes. From examples that use online location software (e.g., Google Street View) to those in video game worlds, virtual rephotography might present convenient windows to unreachable destinations. However, rephotographing without having visited actual vantage points needs to take into account complexity and disjointedness introduced by such tools. Drawing from the author's current practice-led research into photomedia, visual literacy and temporality in Northeastern Japan, emergent particularities are discussed for developing visual literacy through a necessary application of Google Street View.
\end{abstract}

Keywords: Virtual rephotography, visual literacy, photomedia, temporality, Google Street View

\section{Introduction}

Ofunato is a city located on the northeast coast of Japan. Harrowing video footage of the tsunami on March 11,2011 dispels the visual myth of a single wall of water. Instead, it shows a rising sea level first submerging parts of the dock before inundating the area and allowing waves that followed to freely destroy partly submerged buildings and drag them back out to sea (FN311, 2012). Photographs overlooking the city made in the following years from the same fixed positions (i.e., rephotographs) showed how the downtown area was cleared before the land was raised, sea walls erected, and roads re-laid to create a grid of blank spaces, which would eventually be occupied by new buildings of lower height (MLIT, 2020). A pre-existing natural landbank from where the video was made now divides downtown Ofunato into two areas: one of "normality," where pre-tsunami buildings and businesses are a comforting reminder of relative safety, and one of inundation, where risk is regularly cautioned in the form of signs and memorials. Öfunato, along with nearby coastal towns and cities Kuji, Tanohata, Tarō, Miyako, Kamaishi, and Rikuzentakata, was the subject of a funded project titled Finding Time that set out to use a range of photomedia to document change and perspectives on change in the Tohoku region up to and during the 2020 Tokyo Olympic and Paralympic games. ${ }^{1}$ It had been decided that the games would also be known as the "Recovery and Restoration Games," and the official guide book casually invited visitors to Japan to travel to disaster-hit regions and see the restoration for themselves (Tokyo Olympic Committee, 2020). Central to the methodology was rephotography (also known as repeat photography or fixed-point observation), a diverse set of practices that formally began in the natural sciences as a method of visually recording and exploring change in the landscape by revisiting locations in previously made images (McLeod, 2019). A number of preliminary field trips were planned to prepare a participatory rephotography workshop to be carried out with international students in one of the aforementioned cities during the games. At present, the workshop's future is uncertain, but field trips were carried out until widespread concern regarding the coronavirus pandemic.

Beginning in November 2019, the author identified and visited vantage points adopted in the fixed-point observation photographs, providing an understanding of the topographical changes below. Rephotographing vantage points of images made within the area of inundation, however, was nearly impossible. While surrounding mountains provided initial reference points - as per any typical rephotographic survey - few remaining landmarks made it possible to determine distance from those points. Walking around this area, it was more appropriate to produce photographs that would serve as reference points for future rephotography. In other words, there was a clear sense of starting an archive rather than revisiting one. In February 2020, the author briefly visited the same area while traveling between other cities. A third and more extended trip in March 2020 then coincided with a public unveiling of the Olympic Torch outside the new Ōfunato Port Community Center. During this third trip, vantage points in fixed-point 
observation locations were revisited with additional time allocated to reviewing vantage points in the author's previous 'new' photographs. The day after the torch's unveiling, the Olympics (and the research with it) were suspended and travel from Tokyo to the region was discouraged due to the first wave of COVID-19. Although a further trip was possible eight months later (between the second and third waves of the coronavirus), this paper concerns 'trips' made using Google Street View when travel was otherwise not possible. Significantly, not only did these 'visits' complicate the rephotographic experience of Öfunato as a place, but they highlighted a need to critically examine such visual tools, particularly in the context of remote learning.

\section{Photomedia literacy}

The discussion here stems from a study of temporality in photomedia. In her survey of visual literacy definitions, Kędra (2018) noted that many visual literacy studies to date leaned toward supporting skills in 'visual reading,' but less toward 'visual writing' or other visual skills such as 'visual thinking.' If visual literacy is widely recognized as important to 21 st Century education, then familiarity with photomedia is central to developing all visual literacy skills. Additionally, Kress and Van Leeuwen (1996) established that learning about 'writing' with images was something necessary for participating responsibly in contemporary society (e.g., Lester, 2013). However, as Cobley and Haeffner (2009) argued, there is much more to visual communication than what a photograph shows or does not show. In their discussion of digital cameras and users, they made clear that basic questions still existed, such as those surrounding a photographer's intentions, suggesting that, although institutions (e.g., universities) were an ideal arena to teach and develop a "critical literacy" systematically, camera users taught themselves to be critical through selfreflexivity. Unlike analogue photomedia, the technology of digital cameras "allows the cheap generation of many more dispensable pictures which can be discarded at the click of a switch rather than forcing the photographer to wait and be disappointed after paying for their development on paper." (Cobley \& Haeffner, 2009, p. 142). Yet, as they and Sebeok (2001) have pointed out, discussion of nonverbal aspects involved in the decision-making of a photograph are often overlooked.

Johannessen and Boeriis (2019) have recently built on this thinking, acknowledging that the process of making a photograph is where learning occurs. They point out a qualitative difference between looking at the screen of a digital camera and the ground glass of a view camera: that the speed in which the "protext" (the anticipated final image) is visualized differs between types of cameras. For them, this has significant implications for acquiring critical skills regarding the production of photographic images. According to Johannessen and Boeriis (2019), whereas analogue photomedia required the repetitive attention of honing a craft:

[A] contemporary smart phone camera essentially models the entire craft of photography in such a way that photographers do not need any dark-room skills, or skill with or knowledge of shutter speeds, aperture settings, or the sensitivity to light of film. They simply need to know how to operate sliders and buttons in a graphic user interface, or, increasingly to point and click. (p. 20)

Technological developments in the digital camera (e.g., AF assist, focus tracking) shape decisions and learning, meaning that the user can 'concentrate on the enskillment of orienting bodily with the camera in relation to a scene until the protext is apt in terms of social affordances' (Johannessen \& Boeriis, 2019, p. 20). Through self-reflexivity, digital cameras facilitated an increase in what they called "microgenesis," whereby affordances are coupled to feedback loops on the scale of action and perception. However, what they described is an intuitive action of self-location made possible by contrasting a present moment with a previously distinguishable moment. Wherever a screen makes viewing a protext possible using a digital camera, this gesture is essentially a rephotographic one. For example, while taking a photograph, bright light might be observed creeping into the right of the frame, so one might move slightly to the left, taking another photograph to avoid that particularly obtrusive light. Undoubtedly, digital cameras, by virtue of their screens, make rephotography central to a self-reflexivity and thus a desirable level of criticality. However, knowing that the image can be made without cost (i.e., conveniently and quickly) can obscure the possibility of crafting a similar result, albeit through a slower process of contemplation. In other words, it is worth remembering that while digital cameras speed up this process, it does not mean that digital cameras are superior. They offer a means of self-reflexivity through an implicitly rephotographic gesture, but one which is also temporally different from other photomedia. There is, therefore, a need for photomedia literacy $-a$ 
critical understanding of the temporal nuances between types and forms of cameras when producing images. Such a "literacy" is not merely a matter of how to use a specific camera, but also when to use it. Following Cobley and Haeffner (2009), it is also not helpful to think of this literacy as developing a visual language, but rather to think of making photographs as a visual sensibility that is not only the preservation of cameras. Photomedia, as McKenzie noted (2020, p. 1), encompasses a wide range of photographic and video technologies, which extend to online and remote forms, such as Google Street View (GSV). While GSV was used as a tool for initially planning research trips in this study, the COVID-19 pandemic forced the author to reconsider its role and thus examining its temporality in the process.

\section{Virtual Rephotography}

Rephotography as a method of visually recording change in the landscape formally began in the natural sciences before expanding into visual culture (McLeod, 2019). Given the scale of researchers' subjects and the time taken to identify vantage points in photographs made in far-flung parts of the natural world, virtual repeat photography was developed in contrast to what has been termed a "brute-force technique;" it is a means of locating "photographic sites accurately enough that finding them exactly should only take hours of on-the-ground searching, not days." (Hanks et al., 2010, p. 25). While Arc Scene, a three-dimensional viewer extension of Arc Info software used for the process, was data-intensive, Google Earth (GE) became a convenient, quickly improving, and cost-effective alternative (p. 25).

Although the tools offered to virtual repeat photography hold an advantage in saving time and resources, they do not necessarily make rephotographing itself any easier. When artist Richard Kolker was in Hyères, he came across the location in Henri Cartier Bresson's iconic 1932 image of a cyclist rushing past a set of spiral steps. Kolker later visited the site again but with Google Street View, prompting a series of images that revisited locations in other iconic images in photographic history (Kolker, n.d.). In doing so, he realized that finding a vantage point still depended on information that accompanied or was embedded in the original image. His GSV equivalents of street scenes from Stephen Shore's Uncommon Places (2016) were possible because Shore titled the images with actual street names. Conversely, Kolker's version of Andreas Gursky's 'The Rhine, Dusseldorf, Germany' (1999) was more challenging given the river's length and the high degree of post-production Gursky carried out. Thus, the handling of information in an image may prevent recognition, or worse, be misleading. It may also be incomplete: it is often easy to think of GSV as being "all-seeing," but GSV only "captures a slice of life that carries on in the street, so it's not in any way objective although it's generated in a kind of objective process because its automatic and very unphotographic" (Kolker, in-person interview, 2018).

Artist Jenny Odell in her series Re-enactments used available geographical data to identify and revisit locations in GSV images of San Francisco in which she re-enacted poses of anonymous figures. Learning of the distorting effects of the lenses used in 360-degree cameras 'the hard way,' she drew attention to the challenges of replicating computer photographic vision (Odell, n.d.). As seen in GSV, information represents only a fractional understanding of a place at a particular time and is as limited as other photographic images. Great detail and frequent updates may also be less common outside notable urban areas, leaving vantage points sought in lesser captured areas possibly within pixelated blurs. Odell's images were "in real life" (IRL) rephotographs of a virtual world. Similarly, Virtually There (2011) by Andreas Rutkauskas used Google Earth as a starting point to explore the Canadian Rocky Mountains. Downloading GPS tracks from the Internet and virtually revisiting others' hiking routes, he made $8 \times 10$ sized prints of images of planned routes from Google Earth. He then walked those routes, using a $4 \times 5$ camera to rephotograph the vantage points of the GE images he took with him. Interested in landscapes affected by technology, he was concerned with a supposed gap between how landscapes were mapped and how they were experienced (Rutkauskas, 2020). These and other examples of IRL images of 'virtual' spaces, such as modern day rephotographs of 18th century Paris in Assassin's Creed Unity (Plunket, 2014), echo Trudi Smith's understanding of rephotography as a means of "ground-truthing," of verifying observational data (Smith, 2007). However, the COVID-19 pandemic, makes virtual rephotography more tempting.

In situations where IRL rephotography is not possible, it is important to reflect on the term "virtual." According to Marie-Laure Ryan (2016), the term can refer to something appearing present that is actually absent, or it can refer to something fictive in contrast to what is real (pp. 18-19). ${ }^{2}$ Examples of the latter might be in-game rephotography that mimic IRL rephotography, such as the 'A Thousand Words' mission 
in the video game Far Cry New Dawn (Stenhouse, 2019), which simulated the method of holding an old photograph in its original location, characteristic of the popular Dear Photograph project (Jones, 2012). The referent image used for the rephotography is a scene of the 'current' location as 'seen' in a previous iteration of the Far Cry game series. Therefore, the referent is equally unreal as the rephotograph, requiring the user to have specific cultural knowledge (i.e., having played the original game) to understand the reference. While this may not differ so much from needing prior knowledge of a place when rephotographing IRL, there is less opportunity for a user unfamiliar with the reference to encounter and engage with the same vantage point.

The same can be said of two other examples. In On Exactitude in Science (2017), Alan Butler paired Godfrey Reggio's Koyaanisqatsi (1982) with his version Koyaanisgtav (2017) made entirely using in-game photography from within the Grand Theft Auto video game series. Using the original film as a template, scenes were recreated in the game frame-for-frame but only as far as the game-world and the possibilities it afforded would allow (Butler, 2017). Similarly, in Vertigo@Home (2007, 2015), Grégory Chatonsky used GSV to revisit journeys between sites in Alfred Hitchock's film Vertigo (1958), referring to instances where James Stewart's character was following a woman driving around San Francisco as she searched for an imaginary past. By "driving" along the same routes in GSV and pairing it with the original soundtrack, Chatonsky's version revisited the experience of a fictional character played by real actors (Chatonsky, 2007). While his film shared a connection to the actual streets along which Google's camera operator drove, that link was largely symbolic, as was the use of San Francisco as a backdrop for Hitchcock's story. Therefore, both Chatonsky's and Butler's films reference a representation rather than reference a place from which representations are derived; they are parodies. This means that there is a difference between virtual rephotography and rephotographing the virtual.

\section{On virtual ground}

If rephotography is a means of "ground-truthing" reality experienced in visual studies (Smith, 2007), what can virtual rephotography offer researchers and users? Technologies and tools for remote viewing (e.g., Google Street View) have been in use for over a decade. They have been the subject and vehicle for many visual inquiries within contemporary arts. Therefore, virtual experiences are not new. Still wide-scale shifts to online learning in 2020 have led to a renewed spotlight on such techniques and approaches, but mostly as a solution to consumer concerns. At the beginning of the pandemic, copious suggestions were shared to balance self-isolation with the normality of working social life. In particular, Google reported that GSV was being used to offer sightseeing tours (Malcyzk, 2020). More recently, virtual reality content made possible by products such as the Oculus Rift is being touted as a way to sustain interest in travel destinations for the foreseeable future (Debusmann, 2020). Mindful of this outlook, it is the role of those working in the field of visual literacy to examine such visually powerful tools and ensure that there is a space for critically discussing how they are used in a range of contexts. What follows, is an initial contribution to such discussion, drawing upon both empowerment and concerns made apparent by previous virtual rephotography examples. From revisiting Ōfunato using GSV, a set of particularities emerged that may offer a base from which to critically evaluate GSV applications that overstate the tool's symbolic power.

\section{Go where you 'know'}

The author's IRL visits to Ōfunato began at the former train station (now bus station) and a nearby hotel in Nonoda downtown closest to the waterside. The first trip comprised a series of walks that combined seeking out locations in previously made pictures (researched and previewed using maps and GSV) with psychogeographical walks in the area of inundation where the author responded to what was encountered and documented. Initial walks circled out north and south from the hotel, occasionally retracing parts of the same route. By the second night, a point was made for walking around the area of 'normality' on the last morning. Across the first two days, walks occurred at different times of the day, from a prolonged sunrise through to an equally prolonged sunset (tall mountains to the east and west ensures the sun "rises" and "sets" earlier than scheduled). The third trip revisited some of the walks in the first albeit extending even further north along the inundation section. When using GSV to visit Öfunato, following the same paths immediately created comparisons.

Two-minutes-walk south of the hotel were two convenience stores that appeared closed in November 2019. Both had no signage or any indication of use. However, as the majority of convenience stores in Japan 
tend to comprise pre-fabricated buildings, the design of these two closed stores indicated that one was formerly a Lawson (Figure 1); the other a Seven Eleven (Figure 2). Uncertain as to whether the stores were awaiting products and staff to fill them or whether they were to be demolished, both were photographed: one using color sheet film, the other in color using a digital camera. ${ }^{3}$ Too close to the water's edge and too short to withstand the force of the water, it was clear that the convenience stores - as per the hotel and many nearby buildings - had been built since the disaster. During the third trip four months later, both stores were gone: Lawson had been demolished and paved over leaving only a difference in shades of tarmac (Figure 3), and Seven Eleven was in the final stage of being demolished (Figure 4). Browsing the locations in GSV initially presented an image captured from June 2013 revealing only empty plots of land filled with grass and rubble. Having witnessed the stores and subsequently their absence, it seemed appropriate that the next experience was one where they had never existed. Indeed, at the time of capture, the GSV vehicle operator nor anyone inspecting the location (in GSV or IRL) could have known the stores' fates. Without the "with store" and "without store" experiences in person, it would have been impossible to consider the 2013 GSV image capture as anything but a record of destruction. Instead, revisiting a place known to the researcher or user can encourage seeing an empty space for what it will become rather than what it wasn't anymore.

\section{Figure 1}

A Lawson convenience store in the Nonoda area of Öfunato as seen in November 2019.

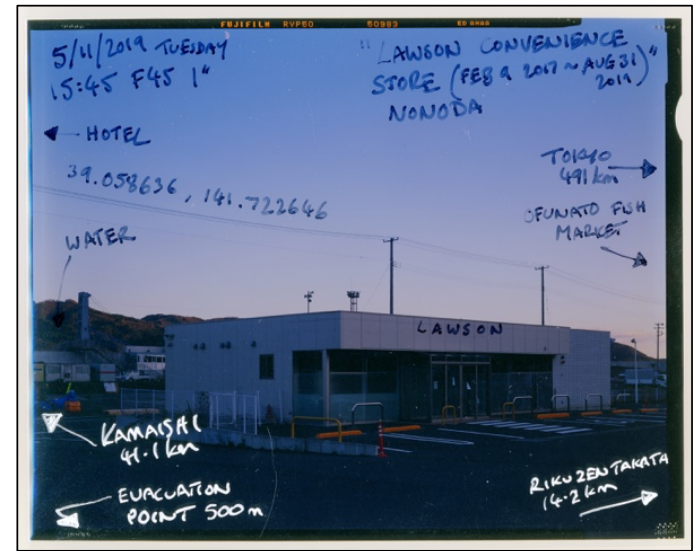

\section{Figure 2}

A Seven Eleven convenience store in the Nonoda area of Öfunato as seen in November 2019, very close to the Lawson convenience store in Figure 1. () The author 2020.

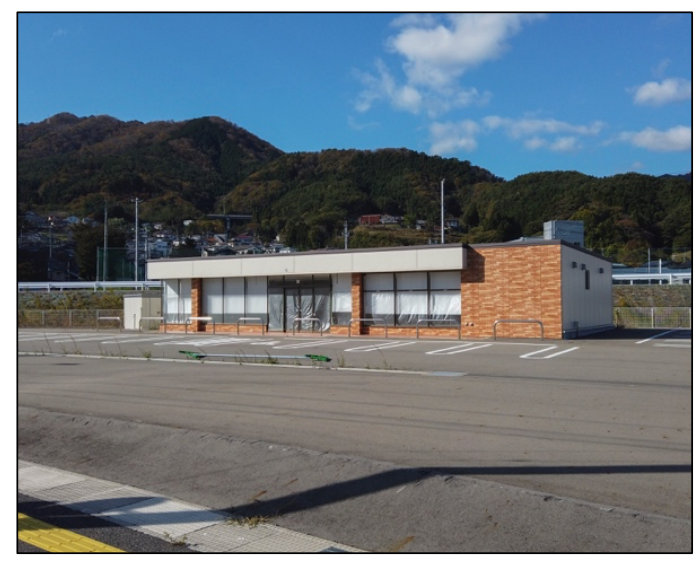




\section{Figure 3}

By March 2020, the Lawson convenience store had been demolished and paved over. Traces of the store remained in the form of different color tarmac. (c) The author 2020.

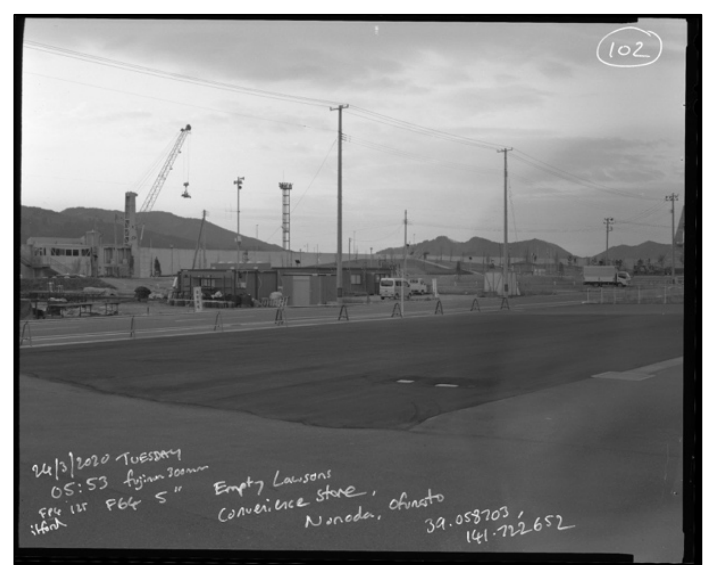

\section{Figure 4}

By March 2020, the Seven Eleven store was in the final stages of being demolished. ( The author 2020.

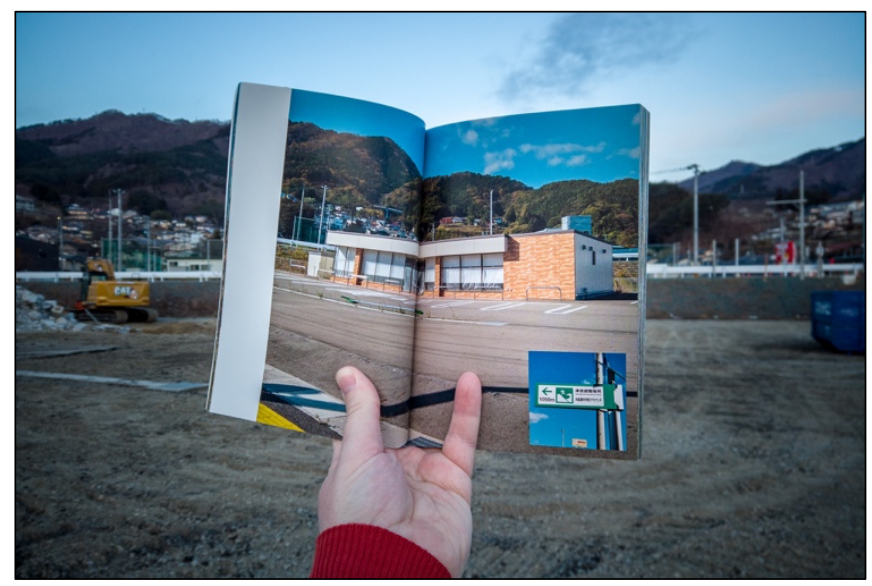

\section{Go forwards by going backwards}

Rephotographing IRL is as much about creating records that can be returned to in the future as it is about recording changes since a previous image was made. As noted above, when unable to identify locations in the inundated area as documented in previous photographs, it was necessary to make new photographs of what was seen that could be revisited later. In doing so, it is important to be mindful of potential changes to the landscape that might yet occur. The simplest example of this is photographing sites where construction is taking place. Conversely, sites of deconstruction or demolition serve as an indicator of possible change, such as the two empty convenience stores noted above. Seasonal changes in local plant life would also be a good example to photograph, but it is perhaps more valuable to note where such plants may be growing. Another instance is political posters, either in the form of local or national representatives. Rephotographing forwards in person is relatively simple were it not for restrictions on travel. However, rephotographing forwards in GSV is unlikely as the technicians at Google are not concerned with specific details of places being revisited over time. Rephotographing backwards is possible with GSV though, particularly if using the web-browser version of the software, which contains a history slider function, thereby 
allowing the researcher or user to select and learn from alternative image captures of the same location.

During the third trip in March 2020, workers had erected scaffolding alongside the Suzaki River, which was photographed with anticipation for what would be constructed (Figure 5). A fourth IRL trip in November 2020 revealed a completed standalone restaurant that was serving customers (Figure 6). Although the location was not recorded during the first trip, panorama views made from the Öfunato Port Community Center showed that nothing on that site indicated possible construction (Figure 7). Earlier captures in 2013, 2014 and 2015 (from another angle) also showed an empty space where surroundings suggested it was waiting to be razed (Figure 8). ${ }^{4}$ The image capture in September 2011 revealed a pile of debris surrounded by skeleton forms of nearby buildings (Figure 9). Unfortunately, the 2011 image capture is also an 'historical wall' whereby — to the best of the author's knowledge — there are no equally and readily accessible image captures before that time. As with many other towns along the coast, Öfunato was only captured by GSV cameras following the disaster, as part of Google's declared effort to document the ongoing recovery (Google 2011). ${ }^{5}$ Any existing photographs from before the disaster are likely in de-centralized and personal archives, or worse, lost to the water. Naoya Hatakeyama wasn't wrong when he noted that the 'the world is now divided into before and after March 11, 2011' (Whatley, 2018, para. 7). If the GSV images are taken to be the entry point into the visual history of Öfunato, the researcher's or user's experience would begin with a record of the disaster's aftermath, as if a version of Ofunato did not exist beforehand. By way of contrast, going up to the roof of the Ōfunato Port Community Center in person can offer a rephotographic experience that acknowledges an earlier visual history. There, aerial and street-level views of the downtown area taken prior to the disaster can be compared to the present-day scene without the need for aftermath images. In this sense, virtual rephotography using GSV is limited and perhaps even unfair to how the city is visually represented: as a city destroyed rather than as a city that survived. Yet, starting with the most recent GSV image and working backwards can redress that concern.

\section{Figure 5}

Scaffolding along the Suzaki river in Ōfunato as photographed in March 2020. (c) The author 2020.

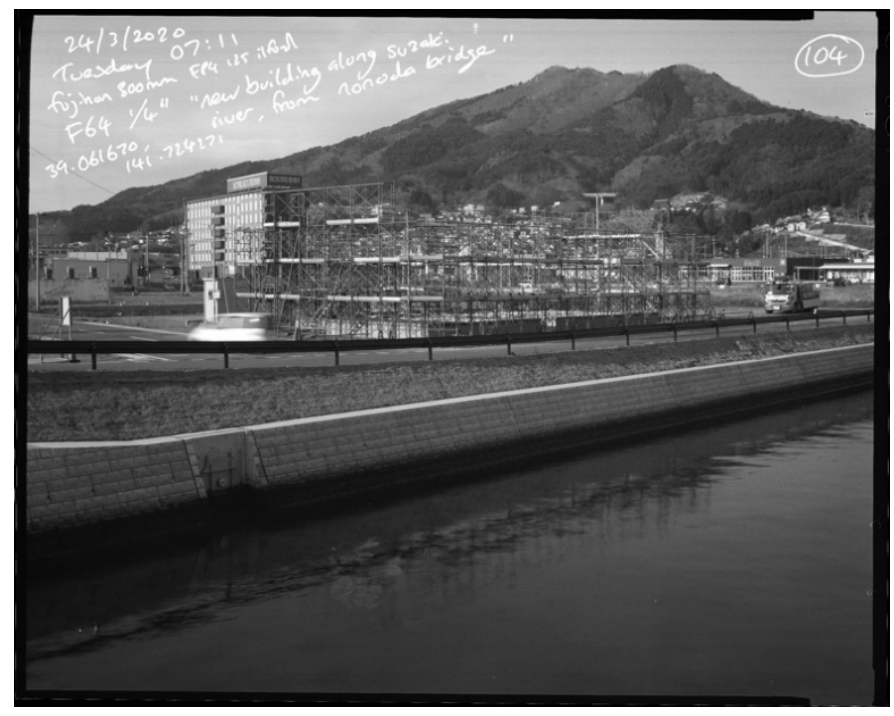




\section{Figure 6}

By November 2020, a standalone restaurant had been built where the scaffolding had been present. () The author 2020.

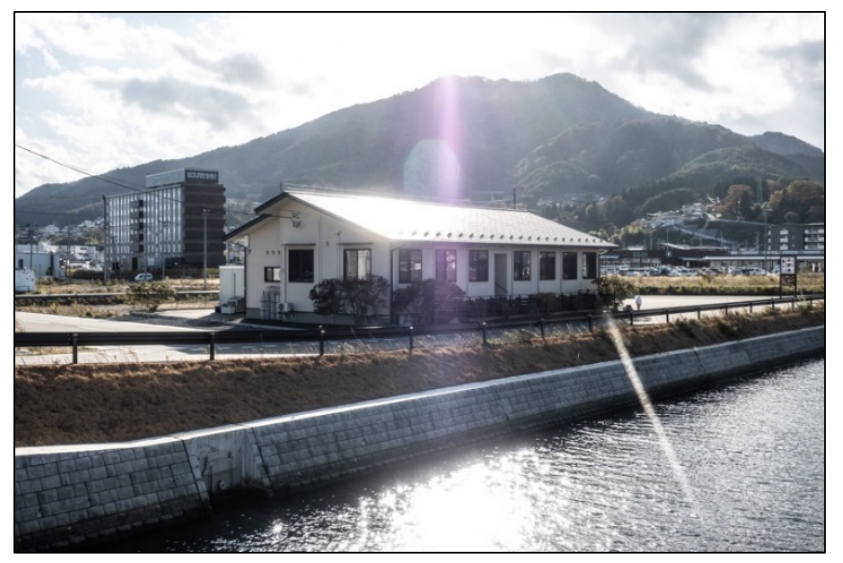

\section{Figure 7}

Detail of a panorama of Ōfunato made in November 2019. At that time, there were no visible indications that the restaurant in Figure 6 would be built. () The author 2020.

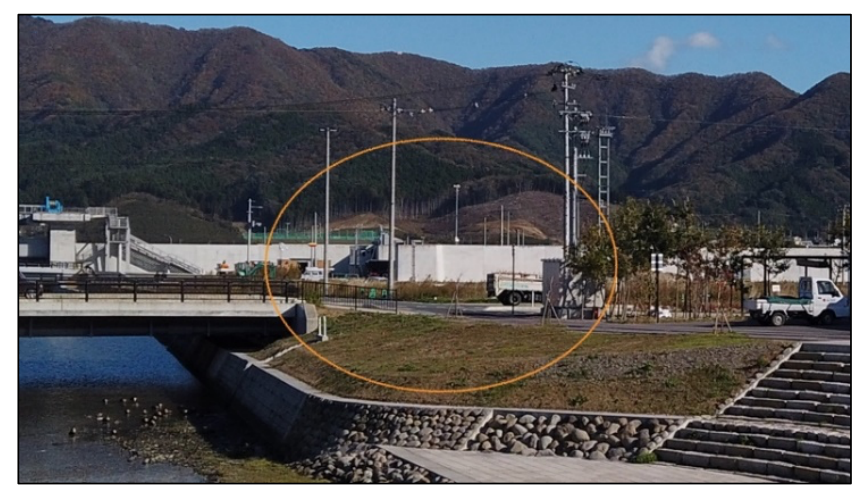

\section{Figure 8}

GSV image captures from 2013, 2014 and 2015 respectively, depicting an empty space where the restaurant in Figure 6 would eventually be built. The 2015 image capture is from a different angle. (@) Google 2020.
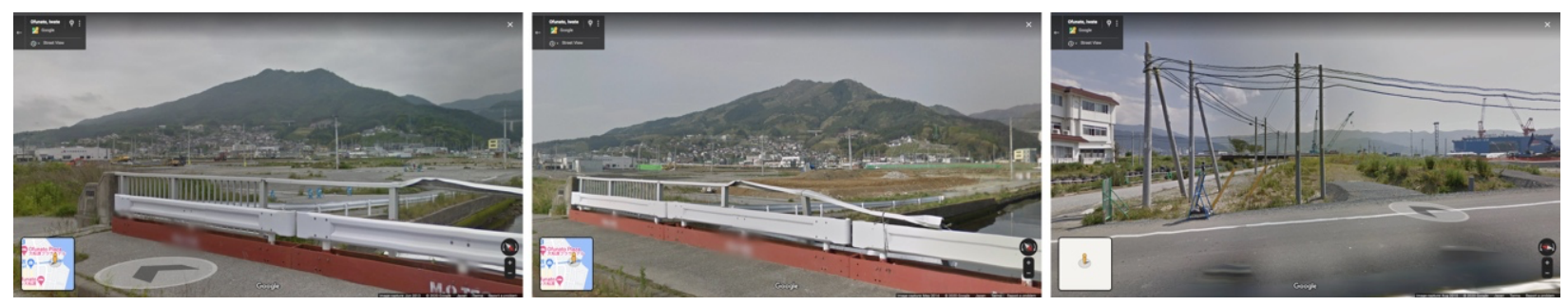


\section{Figure 9}

GSV image capture of the restaurant's location as seen in 2011. The area is surrounded by the skeletal remains of buildings. (c) Google 2020.

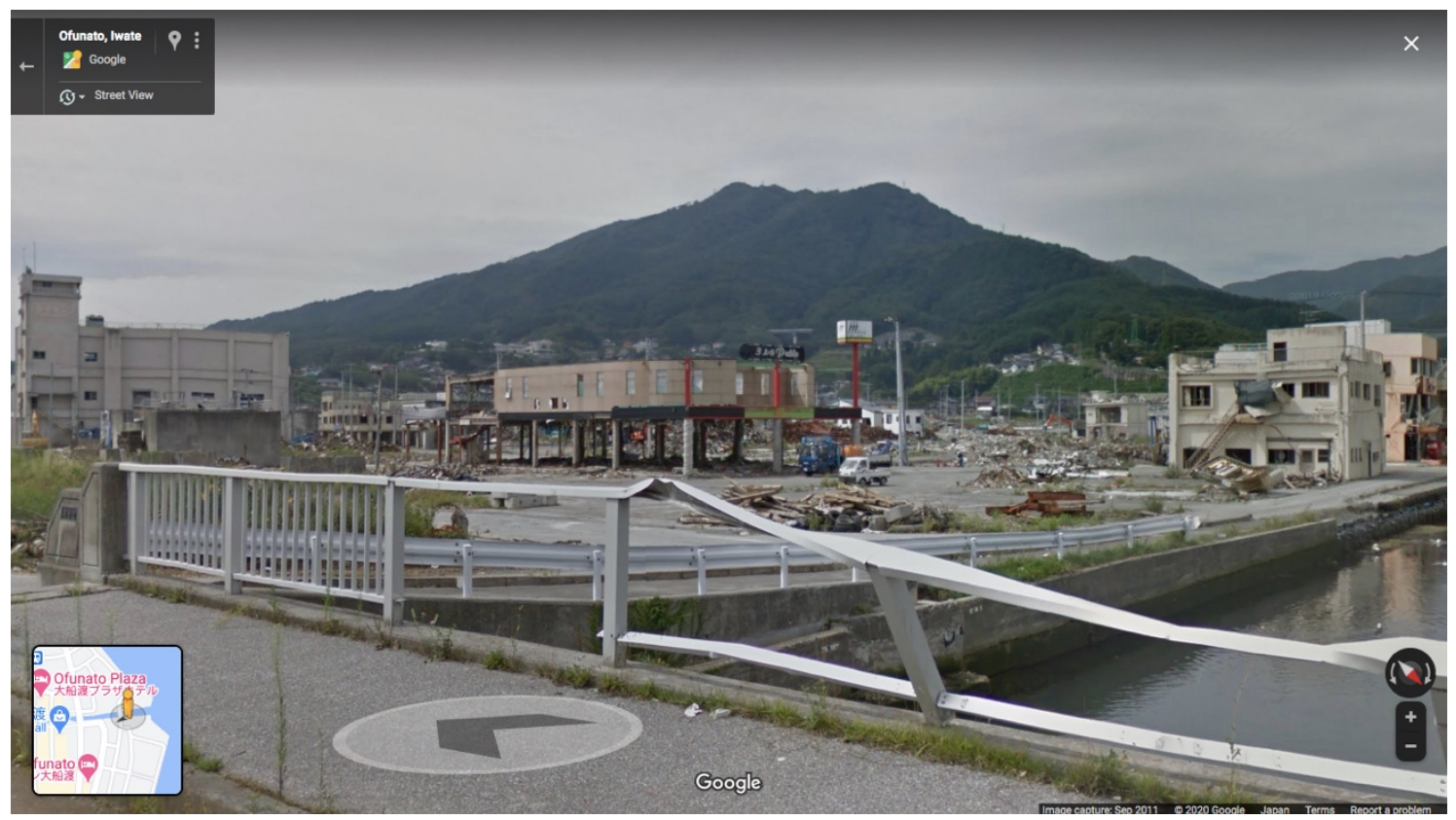

\section{Go with glitches}

It is well known that GSV regularly contains glitches that can appear in a number of circumstances. Some of the most notorious may be errors in stitching together complex scenes, shifts in view when the GSV camera passes other vehicles, or even "messages" from members of the public given in full view and consciousness of the camera's presence (e.g., Wolf, 2019). Moreover, it should be noted that few image captures follow exactly the same paths, making for diversity in weather conditions and lighting but also in the case of places with great amounts of change - making for different road layouts. Nowhere is this as apparent as it is in Ofunato, where the land has been elevated and new roads built. Even if the same routes were followed precisely, the software may not present a continuous experience. According to Google, "when you move to an area in the distance, the 3D model determines the best panorama to show you for that location" (Google, 2020). In the case of Öfunato, as well as other places where change was significant, this makes for a shifting temporal experience. Expecting to continue walking down the same road in June 2013, the view transmogrified to a 2019 view of the same road albeit blocked by the BRT line, which is possible to cross on foot but not by car (Figure 10). What therefore appears visible in the 2013 model is not possible to 'walk' through in the 2019 iteration. This is not unique to Ōfunato, but its commonality depends upon which temporal point of the history slider the user is currently 'in'.

Continuing to "walk" around Ōfunato using GSV can eventually become an unnerving experience; the researcher or user is uncertain about how the view will change. While the history slider offers a modicum of control in that the researcher or user can switch back to the time of the image capture they were browsing, the model will continue to determine what can be viewed and when. For as long as the experience remains, the researcher or user is condemned to "jump" from one time period to another, much like a vaunted time traveler of science fiction. Analogy aside, the experience can be informative but notably disorienting without on-site knowledge. There is a danger of likening such an experience to the rephotography found in video games and parody works noted earlier. Therefore, a key difference is that the rephotographic experience remains unpredictable and random according to the quirks of the software and the modelling/mapping process. Such glitches may be unnerving but they also present opportunities to learn through contrast between the expected and unexpected. 
Figure 10

A GSV image capture in June 2013 unexpectedly transmogrified to a 2019 view of the same road albeit blocked by the BRT line, and no longer accessible by car upon which the camera was mounted. (C) Google 2020.
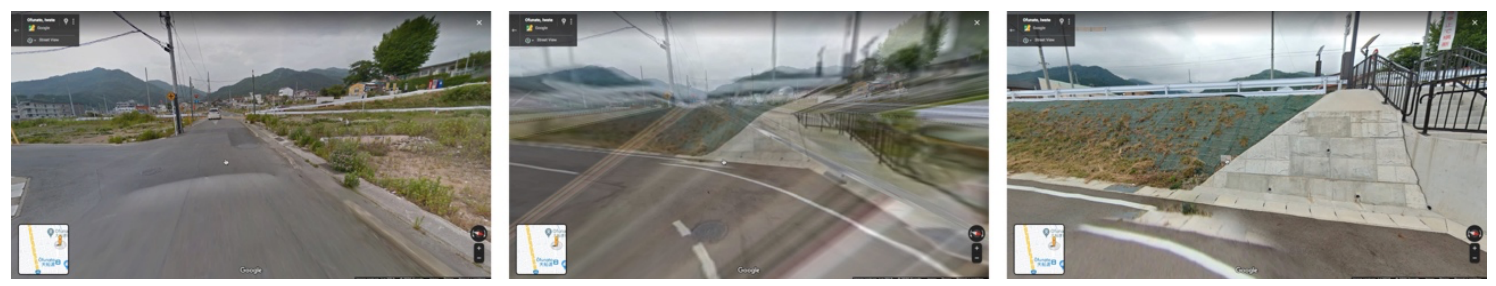

\section{Discussion}

Despite being aware of virtual rephotography, it was never the author's intention to adopt such an approach until it became impossible to do the research in person. When necessary, it was found that GSV brought value to an existing visual project in unexpected ways; but it also encouraged a more critical eye of its affordances. Chief amongst concerns is that GSV is highly limited in that it captures only one time frame out of a whole year's worth of possibilities. Moreover, those choices are usually banal as the GSV camera operator cannot select a view in the way that an everyday camera user can. It is likely then that a GSV image capture cannot and should not stand as representative of a place's diversity. Assigning GSV images with any kind of finality is to forget that very visual and very apparent fact. Despite the ability to 'roam' around the streets, the images are technically photographic 'stills' gathered and presented in a sequence that is not that of the researcher's or users, making for an experience that might otherwise risk a form of psychosis were it not for the screen reality being distinct from that of the researcher or user.

It is also worth remembering that in the wider discussion of visual tools for aiding virtual experiences, GSV is not, and will not be, the definitive form that virtual rephotography can take (as examples earlier in the paper made clear), although similar software such as Baidu Total View in China likely has inherited similar particularities. It is also worth noting that places absolutely existed before GSV cameras visited. While perhaps an obvious point, the power of companies to potentially replace existing archives with GSV image captures (no matter how fantastical that sounds) - or at least control which is likely seen first - should be a cause for concern and discussion in terms of visual literacy. Those learning through making photographs should be amongst some of the first to question such a possibility were it ever to arrive.

In sum, GSV is inherently photomedia, and like all photomedia, it has limitations beyond its compositional differences. Many of those differences are temporal and become discoverable through the virtual experience of rephotographing. The notable particularities that emerged in revisiting Öfunato by way of GSV contribute to the growing need for a photomedia literacy. Photomedia may differ in cost and convenience, but it is in their temporal differences where learning takes place. As a tool for learning visually about a specific location without going there, GSV remains useful. In virtually rephotographing, it becomes a temporally complex yet valuably imperfect tool for that visual research.

\section{References}

Butler, A. (2017). On Exactitude in Science. Artist website [Internet] http://www.alanbutler.info/onexactitude-in-science-2017-1 [Accessed 29 November 2020]

Chandler, S. (2020). Google Street View is Helping Tour Guides Go Virtual. Forbes, 24 April [Internet] http://forbes.com/sites/ [Accessed 29 November 2020]

Chatonsky, G. (2007). Vertigo@home. Artist website [Internet] http://chatonsky.net/vertigo/ [Accessed 29 
November 2020]

Cobley, P. and Haeffner, N. (2009). Digital cameras and domestic photography: communication, agency and structure. Visual Communication, 8:2, 123-146. doi: 10.1177/1470357209102110

Debusmann, B. Jnr. (2020). 'Coronavirus: is virtual reality tourism about to take off?' BBC News, 30 October [Internet] http:// [Accessed 29 November 2020]

Hanks, T.C., Blair, J.L. and Webb, R.H. (2010). Virtual Repeat Photography. In D. E. Boyer, R. M. Turner \& R. H. Webb (Eds.), Repeat Photography: Methods and Applications in the Natural Sciences (pp. 24-31).

FN311, (2012). 大船渡市街地に押し寄せる津波【視聴者提供映像】YouTube [Internet] https://www.youtube.com/watch?v=SR2kOR2Ihf0 [Accessed 29 November 2020]

Google, (2011). Memories for the Future. [Internet] https://www.miraikioku.com/en/ [Accessed 29 November 2020]

Google (2020) Sources of photography. [Internet] https://www.google.com/intl/en_jp/streetview/explore/ [Accessed 29 November 2020]

Jones, T. (2012). Dear Photograph. New York: Harper Collins.

Johannessen, C.M. \& Boeriis, M. (2019). Accelerating semogenesis: an ecosocial approach to photography. Visual Communication https://doi.org/10.1177/1470357219887769 [29 November 2020]

Jurgenson, N. (2019). The Social Photo: On Photography and Social Media. London: Verso.

Kędra, J. (2018). What does it mean to be visually literate? Examination of visual literacy definitions in a context of higher education. Journal of Visual Literacy, 37:2, 67-84. https://doi.org/10.1080/1051144X.2018.1492234

Kolker, R. (Nd). Street-views. Artist website [Internet] https://www.richardkolker.com/street-views [Accessed 29 November 2020]

Kolker, R. (2018). Interview with author. March 2018.

Kress, G. \& Van Leeuwen, T. (1996). Reading Images: The Grammar of Visual Design. London: Routledge.

Lester, P.M. (2013). Visual Communication: Images with Messages. Boston: Wadsworth Publishing.

McKenzie, J. (2020). Light and Photomedia: A New History and Future of the Photographic Image. London: Routledge.

McLeod, G. (2019). Rephotograph (v). Philosophy of Photography. 10:1, 89-99. doi: https://doi.org/10.1386/pop_00008_7

Malczyk, K. (2020). Street View is helping this tour guide stay in business. Google The Keyword, 24 April, [Internet] http://blog [Accessed 29 November 2020]

MILT (2020). Fixed-point observation images. Ōfunato City, Earthquake Memorial Museum [Internet] http://infra-archive311.jp/en/te_Ōfunato_a.html [Accessed 29 November 2020]

Odell, J. (Nd). Re-enactments. Artist website [Internet], https://www.jennyodell.com/reenactments- 
series.html [Accessed 29 November 2020]

Plunket, L. (2014). Assassin's Creed's Paris vs Paris, 2014. Kotaku, 20 November [Internet], https://kotaku.com/assassins-creeds- paris-vs-paris-2014-1664926658 [Accessed 29 November 2020]

Ryan, M.L. (2016). Narrative as Virtual Reality 2: Revisiting Immersion and Interactivity in Literature and Electronic Media. Baltimore: Johns Hopkins University Press.

Sebeok, T.A. (2001). Nonverbal Communication. In P. Cobley (ed.) The

Routledge Companion to Semiotics and Linguistics. London: Routledge.

Shore, S. (2016). Uncommon Places, The complete works. London: Thames and Hudson.

Smith, T. (2007). Repeat Photography as a Method in Visual Anthropology. Visual Anthropology, 20:2, 179-200. doi: 10.1080/08949460601152815

Stenhouse, H. (2019). All dear photograph locations in Far Cry New Dawn. Hyperxgaming, 1 March [Internet] https://ag.hyperxgaming.com/article/7184/all-dear- photograph-locations-in-far-cry-newdawn [Accessed 29 November 2020]

Tokyo Olympic Committee, (2020). Tokyo 2020 Guidebook [Internet] https://tokyo2020.org/jp/games/plan/data/tokyo2020-guidebook-en.pdf. 15.

Whatley, K. (2018). A cloven landscape, a cloven tree, a cloven self. Japan Times, 4 January [Internet], https://www.japantimes.co.jp/culture/2018/01/04/arts/cloven-landscape-cloven-tree-clovenself/\#.XFLoSs8zbsk [Accessed 29 November 2020].

Wolf, M. (2019). Fuck You. Artist website [Internet] http://photomichaelwolf.com/\#fuck-you/1 [Accessed 29 November 2020]

\section{Footnotes}

1. Funded by the Japan Society for the Promotion of Science (JSPS), number: 19 K22994.

2. It should be noted that use of the terms 'in real life' (IRL) and 'virtual' may appear to reinforce what Nathan Jurgenson (2019) has referred to as a 'digital dualism' where the online world is routinely, but inappropriately, considered unreal and the offline world somehow more real. Jurgenson's argument is that the online world has very real influence offline and vice-versa. This is an interesting framework in which to reconsider rephotography and will be the subject of another paper.

3. Circumstances and lighting primarily dictated which camera was used to make these photographs. Seven Eleven was initially photographed as a visual note to the author to return with the large format camera. When returning, the position of the sun did not warrant exposing a valuable sheet of color film.

4. Although image captures were made in Ōfunato in 2019, a relative view for 2019 at the time of writing would not appear from this vantage point.

5. Google Street View had been deployed in Japan since 2008 but had concentrated on major cities and sightseeing locations. Parts of the city of Sendai were affected by the tsunami and these had been added in 2008. Öfunato, however, was not. 


\section{APA citation format $\left(7^{\text {th }}\right.$ edition) for this publication:}

McLeod, G. (2021). Visual literacy and virtual rephotography. In J. Lee, S. M. Christensen, S.

Beene, X. Chen, and W. Huang (Eds.), Visual literacy in the virtual realm: The book of selected readings 2021 (pp. 81-93). International Visual Literacy Association.

https://doi.org/10.52917/ivlatbsr.2021.018 